\title{
THE WILDERNESS INSTRUCTOR
}

\section{Mountaineering and Mountain Rescue-An Introduction}

Steve Donelan

Mountaineering for its own sake is relatively new. While there are some records of earlier ascents that served no practical purpose, such as Rotario of Asti's climb of the 11600 -foot Roche Melon in 1358, ${ }^{1}$ the activity did not become popular until the late 18th and the 19th centuries. One cause for its popularity was a new view of wild nature as both beautiful and challenging. We can find this view expressed in the literature of the French Enlightenment (especially in Rousseau's myth of the Noble Savage), in the early poetry of Goethe (eg, "Harz Mountain Journey in Winter"), and in the works of 19th century Romantic poets like Wordsworth and Shelley. We also find it in the school of German landscape painting, which 19th century painters like Church and Bierstadt brought to the United States, and in the accounts of climbing by early mountaineers. For example, Edward Whymper described the Mont Pelvoux area as follows: ". . . its cliffs, its torrents and its gorges are unsurpassed, its deep and savage valleys present pictures of grandeur and even sublimity, and it is second to none in the boldness of its mountain forms.",2

Another factor that made mountaineering popular was the Industrial Revolution, which created a large middle class of people who had money and leisure for travel, and which also inspired many of them with an interest in science. ${ }^{3}$ As a result, many Alpine expeditions in the 19 th century carried thermometers, barometers, and other instruments to document conditions at high altitude. But alpine climbers were often also driven by a competitive spirit that was intensified by national rivalries as climbers from all over Europe and Great Britain discovered the Alps, and competition encourages people to take risks.

Inevitably, the number of mountaineering accidents increased. In the Alps, the large concentration of climbers in a relatively small area guaranteed enough accidents to keep teams of paid professional rescuers busy, and the professionalizing of mountain rescue created the need for standardized training and certification. The mountains in Great Britain are also concentrated into relatively small areas, although mountain rescue teams are still made up of volunteers, as they are in the United States.

As the authors of the following article point out, training for mountain rescue may need to be modified to fit local conditions. In developing their curriculum for the diploma in mountain medicine in the United Kingdom, for example, they took account of Great Britain's wet climate, which makes it more difficult for mountaineers and rescuers to stay warm and dry, and increases the risk of hypothermia. Indeed, some Scottish mountaineers say that you have not really done a climb unless you have done it "in full conditions." So, the weather tends to be part of the British climbing experience.

In California, by contrast, the benign climate and abundance of high-quality granite has encouraged climbers to push technical difficulty to ever higher levels. A change in weather that would hardly hinder a Scottish climber, however, can strand big wall climbers who are within easy sight of tourists with binoculars. Steep rock that is just barely climbable when dry, becomes impossible when wet. Therefore rescuers in places like Yosemite Valley need to be very adept with the technology of high-angle rescue, as well as being very good rock climbers. Many high-angle rescue techniques are also used by firefighters to evacuate victims from tall buildings and other urban structures. ${ }^{4}$

Most Himalayan climbs, however, would be quite easy at California altitudes and in a California climate. The extreme altitude and cold, as well as the high avalanche danger, leave almost no margin for error, and climbers almost never survive an overnight bivouac near the highest summits, where rescue is virtually impossible. These conditions were dramatized by the tragedy on Mount Everest in May 1996, when a storm stranded many climbers (some of them with little experience) near the summit. ${ }^{5}$

Rescuers in the Himalayas are likely to encounter severe cases of altitude illness and frostbite; therefore, these topics will be prominent in their training curriculum. Another problem highlighted by the Everest tragedy was the effect of high altitude on vision in climbers 
who have had corrective corneal surgery, which was recently studied on Everest by 2 ophthalmologists. ${ }^{6}$ This is just one example of new developments in mountain medicine that can require the updating of curricula.

While the authors of the following article draw on educational theory to plan their curriculum, they have also tested the effectiveness of the teaching methods they employed by a variety of assessment techniques. In fact, a large part of the article deals with the role of assessment in teaching and course planning as a learning tool and for evaluation. As they describe, assessment can be used to involve students in a class and reinforce their grasp of what they have done, as well as for testing.

Although the course designed by the authors is meant for physicians, their ideas are equally applicable to courses for lay people. Perhaps their article will not only encourage readers in other parts of the world to develop similar programs, but also suggest ways that instructors who are already teaching wilderness medicine can make their courses more effective.

\section{References}

1. Flemeng F. Killing Dragons: The Conquest of the Alps. New York, NY: Atlantic Monthly Press; 2000.

2. Whymper E. Scrambles Amongst the Alps in the Years 1860-'69. Berkeley, CA: Ten Speed Press; 1981.

3. Unsworth W. Hold the Heights: The Foundations of Mountaineering. Seattle, WA: The Mountaineers; 1994.

4. Vines T, Hudson S. High-Angle Rescue Techniques. National Association for Search and Rescue. Dubuque, IA: Kendall/Hunt Publishing Company; 1989.

5. Houston C. Going Higher: Oxygen, Man and Mountains. Seattle, WA: The Mountaineers; 1998.

6. Dimming J, Tabin G. Lasik on Mount Everest. J Refract Surg. 2003;19:48-51. 